\title{
Current Distribution on Parallel Conductors for Planar Transformers at High Frequency
}

\author{
Li, Mingxiao; Ouyang, Ziwei; Andersen, Michael A.E.; Wang, Wenbo
}

Published in:

Proceedings of 2021 IEEE 12<sup>th</sup> Energy Conversion Congress and Exposition - Asia

Link to article, DOI:

10.1109/ECCE-Asia49820.2021.9479302

Publication date:

2021

Document Version

Peer reviewed version

Link back to DTU Orbit

Citation (APA):

Li, M., Ouyang, Z., Andersen, M. A. E., \& Wang, W. (2021). Current Distribution on Parallel Conductors for Planar Transformers at High Frequency. In Proceedings of 2021 IEEE 12 Energy Conversion Congress and Exposition - Asia (pp. 663-669). IEEE. Proceedings of the Energy Conversion Congress and Exposition - Asia, Ecce Asia 2021 https://doi.org/10.1109/ECCE-Asia49820.2021.9479302

\section{General rights}

Copyright and moral rights for the publications made accessible in the public portal are retained by the authors and/or other copyright owners and it is a condition of accessing publications that users recognise and abide by the legal requirements associated with these rights.

- Users may download and print one copy of any publication from the public portal for the purpose of private study or research.

- You may not further distribute the material or use it for any profit-making activity or commercial gain

- You may freely distribute the URL identifying the publication in the public portal 


\title{
Current Distribution on Parallel Conductors for Planar Transformers at High Frequency
}

\author{
Mingxiao Li ${ }^{1}$, Ziwei Ouyang ${ }^{1}$, Michael A. E. Andersen ${ }^{1}$ and Wenbo Wang ${ }^{2}$ \\ ${ }^{1}$ Department of Electrical Engineering, Technical University of Denmark, Kongens Lyngby, Denmark, zo@elektro.dtu.dk \\ ${ }^{2}$ Shenzhen Institute of Wide Bandgap Semiconductors
}

\begin{abstract}
In high frequency and high current applications, use of parallel winding connection is becoming common practice in planar transformers. However, the current distribution on each parallel conductor is hard to predict. This paper investigates the effect of the insulation thickness and frequency on the current distribution of parallel conductors. When the copper thickness is much larger than the skin depth, the current on each parallel conductor becomes constant. Different layers have varying insulation thicknesses, which is often observed when printed circuit boards (PCB) are fabricated. This also result in unbalanced currents. Based on a 1D model, this paper proposes a methodology for determining the parallel current distribution, specifically used to the $N: 1$ transformer when the copper thickness is much larger than the skin depth. No complex calculation algorithm or simulation software is required. Both finite element analysis (FEA) and theoretical model support the effectiveness of the proposed methodology, which can be used for many parallel structures. The experiment further verifies the theoretical analyses: the current on each parallel conductor is always constant at high frequency; the insulation thickness affects the current distribution.
\end{abstract}

Index Terms-High frequency, planar transformers, parallel current distribution.

\section{INTRODUCTION}

Planar transformers have been widely adopted in many switched-mode power supplies to achieve both high efficiency and high power density, because they are recognized for their low profile, excellent repeatability of construction, ease of manufacture and predictable parasitic components [1]-[6].

In high current high frequency (up to $\mathrm{MHz}$ ) applications, a low output voltage tends to be required for many DC/DC power conversions, such as data centers and telecoms [7]-[10]. The secondary winding usually has fewer number of turns and sometimes only a single turn. Connecting several conductors in parallel can handle the large secondary current. This is recognized as common practice in order to reduce the DC current density. Furthermore, the parallel connections also allow the implementation of interleaved winding layouts to reduce the winding loss at high frequency [11]-[13].

However, the current on each parallel conductor is usually unbalanced, as discussed in [14]. Fig.1 shows a 2:1 transformer with three different winding layouts. 2 layers are connected in parallel to form one turn secondary winding. The ANSYS 2D simulation illustrated different current distributions on parallel conductors. Even the interleaved winding arrangements yield different current distributions.

Much excellent research has been carried out to investigate the current distribution in parallel conductors. FEA simulation tool is applicable, but extremely time-consuming for optimal design. A number of studies [15]-[18] compare several parallel winding layouts via FEA simulation, but no mathematical model or analytical solution is given. Previous modeling efforts offer several analytical approaches to determine current sharing among parallel conductors [19]-[24]. Paper [23] proposes a systematic approach to predict AC resistance and inductance based on a lumped circuit model. Literature [24] presents a mathematical model to calculate the current on each parallel conductor. However, both of these methods require complex calculations for multiple turns in parallel. The current distribution at high frequency has not been investigated.

This paper provides insight into the current distribution on parallel conductors at high frequency. The analysis of the effect of insulation thickness and frequency in this paper reveals that the current on every parallel conductor does not change with frequency when the copper thickness $h$ is much larger than the skin depth $\delta_{w}$, and the interleaved winding layouts with different insulation thicknesses may result in a loss of the advantage of good current sharing.

Based on a 1D model, this paper proposes a straight forward methodology consisting of three rules for determining the current on each parallel conductor, specifically used for the $N: 1$ transformer when $h>>\delta_{w}$. This method is not limited to fully interleaved winding layout, but can be applied to many parallel connections. No complex calculation algorithm or simulation tool is required. This methodology is applied to a fully interleaved winding arrangements to determine the parallel current distribution. FEA simulations support the validity of the proposed approach. The calculated AC resistance demonstrate excellent agreement with the FEA simulated AC resistance.

The experiment results further prove the validity of theoretical analyses: when $h>>\delta_{w}$, the current on each parallel conductor does not change with frequency; the insulation thickness affects the current distribution.

\section{Parallel CurRent Distribution Principle}

The method to predict the current distribution of the $N: 1$ planar transformer is proposed in the subsequent part based on the following assumptions and constraints:

1. The transformer turn ratio is $N: 1$ with primary windings connected in series and secondary windings connected in parallel;

2. Each layer has the same copper thickness $h$ which is much larger than the skin depth $\delta_{w}$;

3. Conductors are closely spaced and the spacing (or the insulation thickness) is identical for every layer;

4. Edge and end effect of the conductors are not considered; 


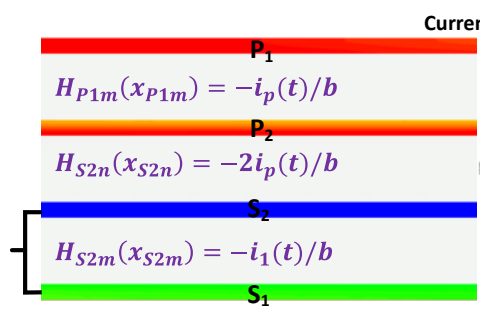

(a) Case I

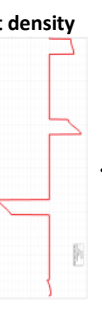

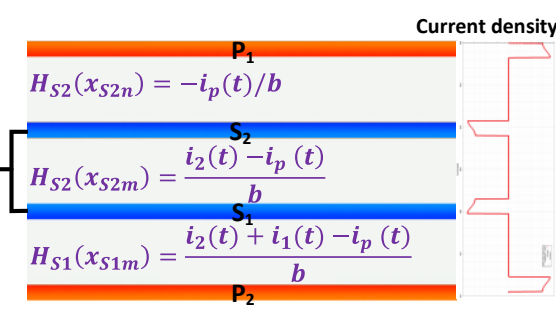

(b) Case II

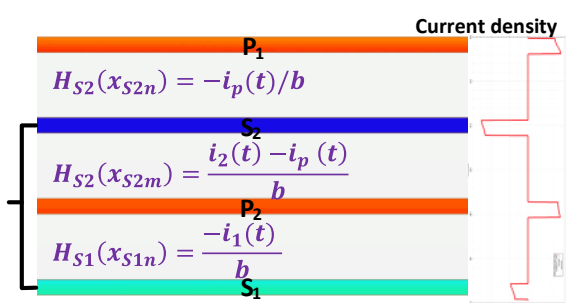

(c) Case III

Fig.1 Three winding parallel schemes of a turn ratio 2:1 planar transformer with primary layers series connected and secondary layers parallel connected

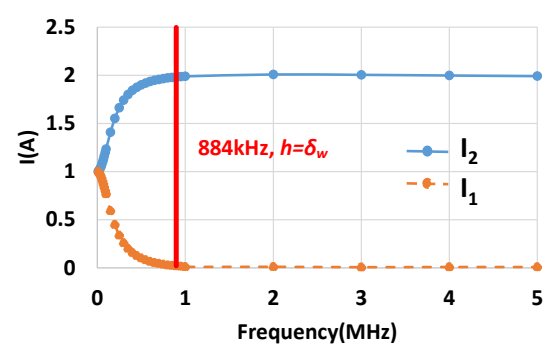

(a) Case I

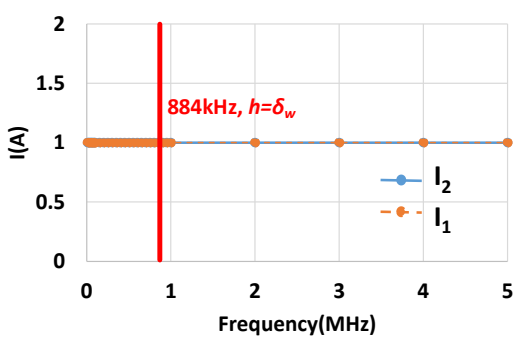

(b) Case II

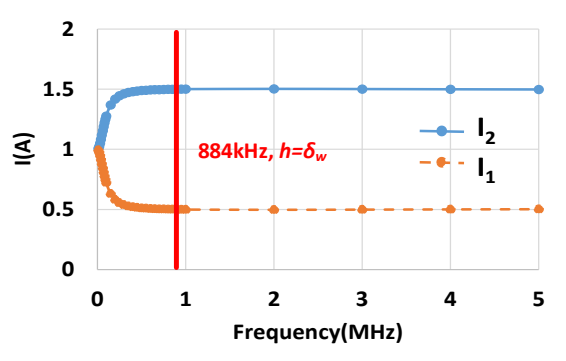

(c) Case III

Fig.2 Current distribution as a function of frequency sweeping from $10 \mathrm{kHz}$ to $5 \mathrm{MHz}$ for (a) Case I (b) Case II and (c) Case III

5. The magnetic core is ideal, i.e., $\mu_{c}=\infty$ and $\rho_{c}=\infty$, where $\mu \mathrm{c}$ and $\rho c$ are the relative permeability and the resistivity of the magnetic core, respectively;

6. A sinusoidal current flows through primary conductors:

$$
i_{p}(t)=I_{p} \sin (w t)
$$

The method consisting of three rules are given as follows:

- Rule 1: Primary and secondary currents attract each other. The current carried by the primary conductors is always equally divided to the top and bottom surfaces when the primary conductors are sandwiched by two secondary conductors. If primary conductors only have one secondary neighbor, all primary current tends to the surface adjacent to the secondary conductor.

- Rule 2: Currents carried by adjacent primary/secondary windings repel each other. If the parallel secondary conductors are placed in adjacent layers, the current on each conductor is drawn to the surface next to the primary windings, while no current is on the other surface contiguous with other secondary conductors. For primary winding, the current on each conductor tends to the surface adjacent to the secondary winding.

- Rule 3: The current on each secondary conductor is the sum of the primary current adjacent to its two surfaces.

TABLE I

WINDING DETAILS

\begin{tabular}{lc}
\hline \hline Parameters & Values \\
\hline Copper thickness $(h)$ & $70 \mu \mathrm{m}$ \\
Turn ratio $(n: 1)$ & $2: 1$ \\
Insulation thickness $\left(t_{h}\right)$ & $0.3 \mathrm{~mm}$ \\
Window width $(b)$ & $9.275 \mathrm{~mm}$ \\
Resistivity $(\rho)$ & $1.71 \times 10^{-8} \Omega \cdot \mathrm{m}$ \\
Air permeability $\left(\mu_{o}\right)$ & $4 \pi \times 10^{-7} \mathrm{H} / \mathrm{m}$ \\
Magnetic core & $\mathrm{E} 32 / 6 / 20$ \\
Mean turn length $(M T L)$ & $20.32 \mathrm{~mm}$ \\
\hline \hline
\end{tabular}

Three parallel winding layouts are shown in Fig.1 to support the proposed method. The primary conductors $\mathrm{P}_{1}$ and $\mathrm{P}_{2}$ are connected in series. A sinusoidal current with $1 \mathrm{~A}$ peak is injected to each primary conductor. The secondary conductors $S_{1}$ and $S_{2}$ are in parallel. As seen from the current density distribution made by ANSYS 2D simulation, the current on each parallel conductor is different.

TABLE I gives details about the winding arrangements. Fig.2 illustrates the current distributed on $S_{1}$ and $S_{2}$ as a function of the frequency sweeping from $10 \mathrm{kHz}$ to $5 \mathrm{MHz}$. From above $884 \mathrm{kHz}$ where $h=\delta_{w}$, the two parallel conductors $\mathrm{S}_{1}$ and $\mathrm{S}_{2}$ always carry the constant current independent of frequency. . In Case I, the $S_{2}$ conducts around $2 \mathrm{~A}$, while the $\mathrm{S}_{1}$ has nearly zero current. In Case II, the $S_{2}$ conducts around $1 \mathrm{~A}$, which is almost identical to the $S_{1}$. In Case III, the $S_{1}$ and the $S_{2}$ carry about $1.5 \mathrm{~A}$ and $0.5 \mathrm{~A}$, respectively. At low frequency, the currents in parallel conductors are changing with frequency for both Case I and Case III. Constant current is observed in Case II at any frequency.

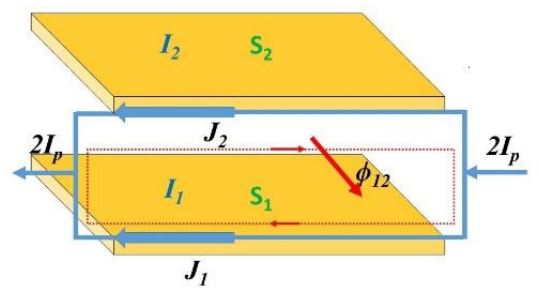

Fig.3. Modelling of two parallel layers

The current distribution is analyzed in the subsequent parts based on the same assumptions given initially in this Section. The model is illustrated in Fig.3. The current distribution in parallel conductors can be derived by Faraday's law and Kirchhoff's law. The magnetic flux $\phi_{12}$ flowing through the space between conductors $S_{1}$ and $S_{2}$ can be written as functions of the current densities $\left(J_{l}\right.$ and $\left.J_{2}\right)$ on the surfaces. Assume the primary windings perfectly couple with secondary windings. The sum of the secondary currents is thus $2 i_{p}(t)$, such that

$$
\underbrace{\rho l}_{\Omega \cdot \mathrm{m}^{2}}(\underbrace{J_{1}-J_{2}}_{\mathrm{A} / \mathrm{m}^{2}})=\underbrace{j w \phi_{1}}_{\mathrm{V}}
$$




$$
i_{1}(t)+i_{2}(t)=2 i_{p}(t)
$$

where $\rho$ is the resistivity of the conductor; $l$ is the conductor mean turn length (MTL); $J_{I}$ is the current density along the top surface of the conductor $\mathrm{S}_{1} ; J_{2}$ is the current density along the bottom surface of the conductor $S_{2} ; \phi_{12}$ is the magnetic flux going through the space between two parallel conductors; $i_{1}(t)$ and $i_{2}(t)$ are the currents conducted by $S_{1}$ and $S_{2}$, respectively. $J_{1}, J_{2}$ and $\phi_{12}$ can be expressed by the induced magnetic field $H$, which is expressed by $i_{1}(t)$ and $i_{2}(t)$. Combining (2) and (3), the current distributions on parallel conductors are solved.

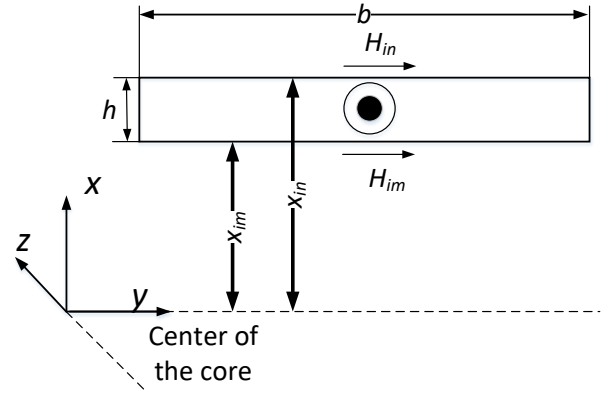

Fig.4. Boundary conditions for $i^{\mathrm{t}}$ layer of a transformer

The magnetic field inside the conductor is described by the Helmholtz equation.

$$
\frac{d^{2} H_{s 2}(x)}{d x^{2}}=\gamma^{2} H_{s 2}(x)
$$

The complex propagation constant $\gamma$ is

$$
\gamma=\frac{1+j}{\delta_{w}}
$$

The skin depth $\delta_{w}$ is given by

$$
\delta_{w}=\sqrt{\frac{\rho}{\pi f \mu_{o}}}
$$

where $f$ is the frequency and $\mu_{o}$ is the air permeability.

The center of the coordinate system is located in the center of the core, as shown in Fig.4, where $x_{i n}$ and $x_{i m}$ represent the distance from $y$ axis to the top and bottom surfaces of the $i^{\text {th }}$ conductor, respectively. From the boundary conditions $H_{i m}$ and $H_{i n}$, the magnetic field $H_{i}(x)$ inside the $i^{\text {th }}$ conductor is given by

$$
H_{i}(x)=\frac{H_{i n} \sinh \left(\gamma\left(x-x_{i m}\right)\right)-H_{i m} \sinh \left(\gamma\left(x-x_{i n}\right)\right)}{\sinh (\gamma h)}
$$

The current density for the $i^{\text {th }}$ conductor $J_{i}(\mathrm{x})$ is

$$
J_{i}(x)=-\frac{d H_{i}(x)}{d x}
$$

Based on the magnetic field in each insulation layer given in Fig.1, the magnetic flux $\phi_{12}$ for each case can be determined. In Case I, the magnetic flux $\phi_{12}$ is

$$
\phi_{12}=u_{o} l t_{h} \cdot H_{S 2}\left(x_{S 2 \mathrm{~m}}\right)
$$

In Case II, the magnetic flux $\phi_{12}$ is

$$
\phi_{12}=u_{o} l t_{h} \cdot H_{S 2}\left(x_{S 2 m}\right)
$$

In Case III, the magnetic flux $\phi_{12}$ is

$$
\phi_{12}=u_{o} l\left(t_{h} \cdot H_{S 2}\left(x_{S 2 m}\right)+t_{h} \cdot H_{S 1}\left(x_{S 1 n}\right)\right)
$$

where $t_{h}$ is the insulation thickness; $H_{s 2}\left(x_{S 2 m}\right)$ and $H_{s 1}\left(x_{S I n}\right)$ are magnetic fields in the insulation as given in Fig.1. $H_{s 2}\left(x_{S 2 m}\right)$ is the magnetic field along the bottom surface of the conductor $S_{2}$ and $H_{S I}\left(x_{S I n}\right)$ is the magnetic field along the top surface of the conductor $S_{l}$. Combining (2), (3) and (7) to (11), $i_{1}(t)$ and $i_{2}(t)$ for each case are solved. For Case I, the expressions for $i_{1}(t)$ and $i_{2}(t)$ can be found in the appendix (A.1) and (A.2). For Case II, the expressions for $i_{1}(t)$ and $i_{2}(t)$ are

$$
\left\{\begin{array}{l}
i_{1}(t)=I_{p} \sin (\omega t) \\
i_{2}(t)=I_{p} \sin (\omega t)
\end{array}\right.
$$

For Case III, the expressions for $i_{1}(t)$ and $i_{2}(t)$ are

$$
\begin{aligned}
& i_{1}(t)=I_{p}\left(\begin{array}{c}
\frac{j w u_{o} t_{h}\left(\sin (w t)-\frac{1}{2}\right) \cdot \sinh (\gamma h)}{j w u_{o} t_{h} \cdot \sinh (\gamma h)-\gamma \rho \cdot \cosh (\gamma h)} \\
-\frac{\gamma \rho\left(\left(\sin (w t)-\frac{1}{2}\right) \cdot \cosh (\gamma h)+\frac{1}{2}\right)}{j w u_{o} t_{h} \cdot \sinh (\gamma h)-\gamma \rho \cdot \cosh (\gamma h)}
\end{array}\right) \\
& i_{2}(t)=I_{p}\left(\begin{array}{c}
\frac{\left(\sin (w t)+\frac{1}{2}\right) \cdot j w u_{o} t_{h} \cdot \sinh (\gamma h)}{j w u_{o} t_{h} \cdot \sinh (\gamma h)-\gamma \rho \cdot \cosh (\gamma h)} \\
\quad-\frac{\gamma \rho \cdot\left(\left(\sin (w t)+\frac{1}{2}\right) \cdot \cosh (\gamma h)-\frac{1}{2}\right)}{j w u_{o} t_{h} \cdot \sinh (\gamma h)-\gamma \rho \cdot \cosh (\gamma h)}
\end{array}\right)
\end{aligned}
$$

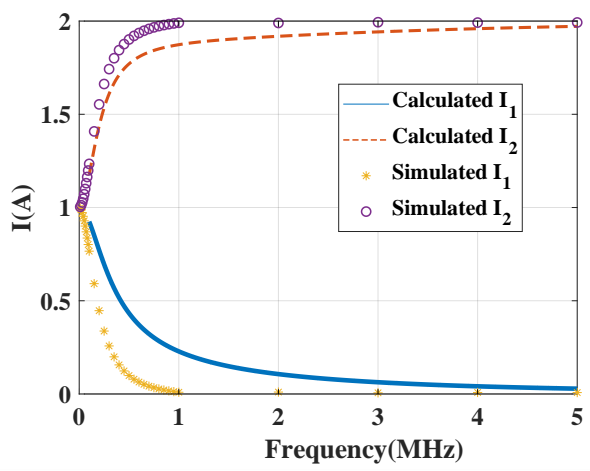

(a)

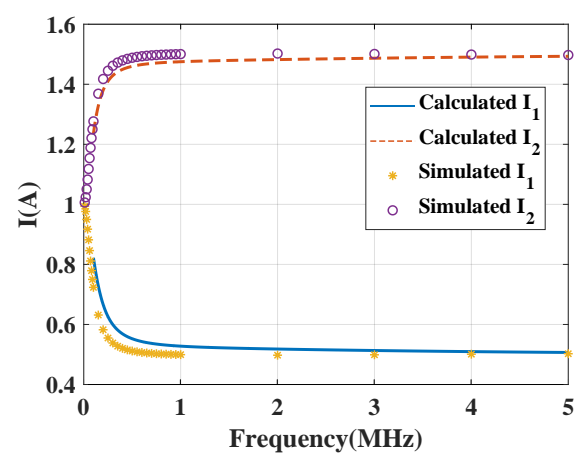

(b)

Fig.5. Comparison between the simulated and calculated current distribution for (a) Case I and (b) Case III

\section{A. Frequency effect on parallel current}

Fig.5 shows $I_{1}$ and $I_{2}$ as a function of the frequency for Case I and Case III. The calculated instants $I_{l}$ and $I_{2}$ are peak currents. There is a minor gap between the calculation and simulation, because we assume the primary winding perfectly couples with secondary winding. The theoretical results match the simulation: $I_{1}$ and $I_{2}$ are constant at high frequency. Case II is not given as the current on each parallel conductor is obviously constant from (12). 
Fig.6 shows the simulated magneto motive force (MMF) for Case II from $100 \mathrm{kHz}$ to $5 \mathrm{MHz}$. Following Ampère's circuital law which links the magnetic field to current, Fig. 6 indicates that currents carried by adjacent primary and secondary conductors attract each other. This is primarily because the primary and secondary windings conduct currents in opposite directions. Considering the proximity effect and skin effect, it is reasonable to observe the current tend to surface next to the other side windings. Conversely, currents carried by two adjacent secondary conductors repel each other, as they are in the same direction.

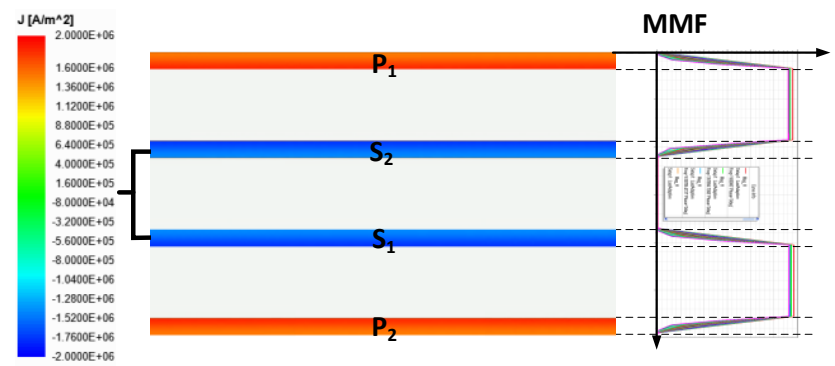

Fig.6. MMF distribution of Case II

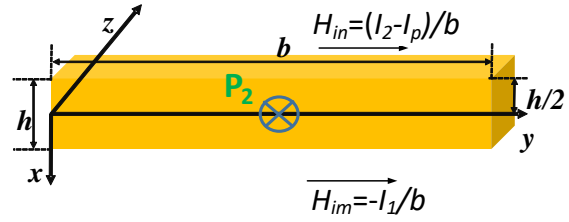

Fig.7. Coordinate system for $\mathrm{P}_{2}$ in Case III

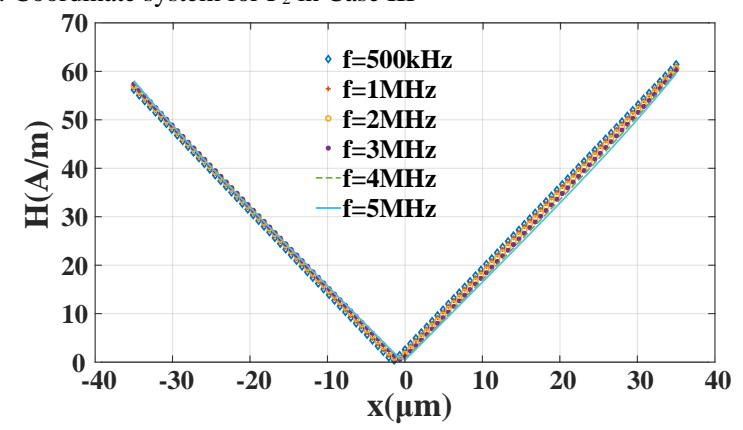

Fig.8. Absolute $H$ field distribution inside $\mathrm{P}_{2}$ in Case III

It is also worthy to prove that at high frequency the primary current is always equally divided to the top and bottom surfaces when the primary conductor is sandwiched between the two secondary conductors, as shown in Case III. Fig.7 shows the boundary conditions for the conductor $\mathrm{P}_{2}$ at $w t=\pi / 2$. The center of the coordinate system is located in the middle of the $\mathrm{P}_{2}$ left side. Based on the magnetic field general expression given in (7), the magnetic field $H_{P 2}$ in the conductor $\mathrm{P}_{2}$ is

$$
H_{P 2}=\frac{\left(I_{p}-I_{2}\right) \cdot \sinh \left(\frac{\gamma(h-2 x)}{2}\right)+I_{1} \cdot \sinh \left(\frac{\gamma(2 x+h)}{2}\right)}{b \sinh (\gamma h)}
$$

Fig.8 illustrates the absolute $\left|H_{P 2}\right|$ distribution in conductor $\mathrm{P}_{2}$ at different frequencies. The $H$ fields are almost identical at two boundaries, $x=-35 \mu \mathrm{m}$ and $x=35 \mu \mathrm{m}$. Hence, following Ampère's circuital law, the primary current is always equally distributed to the two surfaces of the conductor when $h>>\delta_{w}$, as long as the winding layouts satisfy the assumptions and constraints mentioned initially in this section. The sandwiched primary conductor set the two boundary conditions of their two neighboring secondary conductors. The other two boundary conditions of the secondary conductors is determined by the other conductors which has no effect on the current distribution of the sandwiched primary conductor.

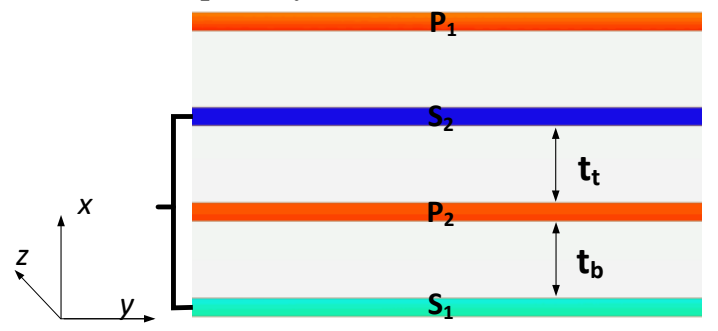

Fig.9. Case III with different insulation

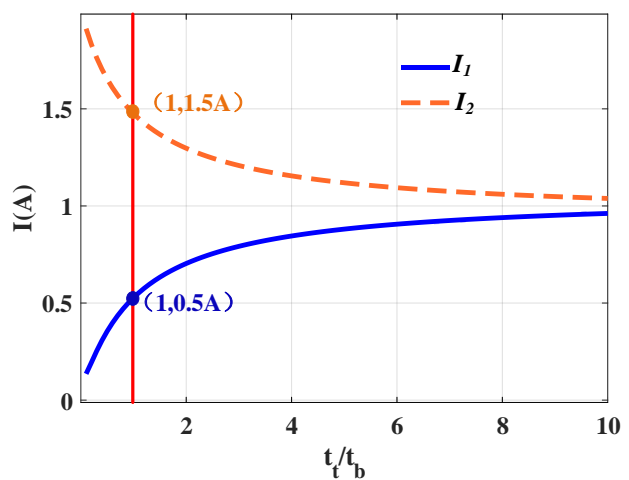

Fig.10. $I_{l}$ and $I_{2}$ versus insulation ratio $t_{l} / t_{b}$ with $t_{t}+t_{b}=0.6 \mathrm{~mm}$ for Case III

\section{B. Insulation effect on parallel current distribution}

In the above analysis, the insulation thickness $t_{h}$ is assumed to be $0.3 \mathrm{~mm}$ for each layer. However, many PCBs' insulation thickness varies from layer to layer due to the fabrication technique. This affects the parallel current distribution dramatically.

Cases III involves two insulation layers to calculate the flux $\phi_{12}$ between two parallel secondary conductors. Assume the two insulation layers are now different, as shown in Fig.9, then the magnetic flux $\phi_{12}$ becomes

$$
\phi_{12}=u_{o} l\left(t_{t} \cdot H_{S 2}\left(x_{S 2 n}\right)+t_{b} \cdot H_{S 1}\left(x_{S 1_{m}}\right)\right)
$$

Expressions for $i_{1}(t)$ and $i_{2}(t)$ change to

$$
\begin{aligned}
& i_{1}(t)=I_{p}\left(\begin{array}{c}
\frac{j w u_{o} t_{t} \cdot(2 \sin (w t)-1) \cdot \sinh (\gamma h)}{j w u_{o}\left(t_{b}+t_{t}\right) \cdot \sinh (\gamma h)-2 \gamma \rho \cdot \cosh (\gamma h)} \\
-\frac{\gamma \rho((2 \sin (w t)-1) \cdot \cosh (\gamma h)+1))}{j w u_{o}\left(t_{b}+t_{t}\right) \cdot \sinh (\gamma h)-2 \gamma \rho \cdot \cosh (\gamma h)}
\end{array}\right) \\
& i_{2}(t)=I_{p}\left(\begin{array}{c}
\frac{j w u_{o}\left(2 t_{b} \sin (w t)+t_{t}\right) \cdot \sinh (\gamma h)}{j w u_{o}\left(t_{b}+t_{t}\right) \cdot \sinh (\gamma h)-2 \cdot \gamma \rho \cdot \cosh (\gamma h)} \\
-\frac{\gamma \rho((2 \sin (w t)+1) \cdot \cosh (\gamma h)-1)}{j w u_{o}\left(t_{b}+t_{t}\right) \cdot \sinh (\gamma h)-2 \cdot \gamma \rho \cdot \cosh (\gamma h)}
\end{array}\right)
\end{aligned}
$$

As the parallel current is proved to be constant when $h>>\delta_{w}$, the frequency is set at $1 \mathrm{MHz}$ to analyze the insulation effect. Fig.10 shows peak currents $I_{l}$ and $I_{2}$ changes with $t_{t} / t_{b}$ under the constant $t_{t}+t_{b}=0.6 \mathrm{~mm}$. Larger ratio $t_{t} / t_{b}$ leads to an almost balanced current distribution. Lower ratio $t_{t} / t_{b}$ shows more current on $S_{2}$ but much lower current on $S_{1}$. The interleaved winding layout has lost its benefit on better current distribution. 


\section{INVESTIGATION OVER FULLY INTERLEAVED WINDING STRUCTURE}

The proposed method is further verified by a fully interleaved parallel winding schemes for an 8-layer planar transformer with a 4:1 turn ratio, as shown in Fig.11. Each has 4 primary layers connected in series and 4 secondary layers in parallel. Other parameters keep the same with TABLE I. The insulation thickness is identical for each layer.

TABLE II

CASE IV: CURRENT DISTRIBUTION

\begin{tabular}{|c|c|c|c|c|c|c|c|c|c|c|c|c|c|c|c|}
\hline \multicolumn{2}{|c|}{$\mathrm{P}_{1}$} & \multicolumn{2}{|c|}{$\mathrm{S}_{1}$} & \multicolumn{2}{c|}{$\mathrm{P}_{2}$} & \multicolumn{2}{c|}{$\mathrm{S}_{2}$} & \multicolumn{2}{c|}{$\mathrm{S}_{3}$} & \multicolumn{2}{c|}{$\mathrm{P}_{3}$} & \multicolumn{2}{|c|}{$\mathrm{S}_{4}$} & \multicolumn{2}{c|}{$\mathrm{P}_{4}$} \\
\hline $\mathrm{T}$ & $\mathrm{B}$ & $\mathrm{T}$ & $\mathrm{B}$ & $\mathrm{T}$ & $\mathrm{B}$ & $\mathrm{T}$ & $\mathrm{B}$ & $\mathrm{T}$ & $\mathrm{B}$ & $\mathrm{T}$ & $\mathrm{B}$ & $\mathrm{T}$ & $\mathrm{B}$ & $\mathrm{T}$ & $\mathrm{B}$ \\
\hline 0 & $\mathrm{I}$ & $\mathrm{I}$ & $\mathrm{I} / 2$ & $\mathrm{I} / 2$ & $\mathrm{I} / 2$ & $\mathrm{I} / 2$ & 0 & 0 & $\mathrm{I} / 2$ & $\mathrm{I} / 2$ & $\mathrm{I} / 2$ & $\mathrm{I} / 2$ & $\mathrm{I}$ & $\mathrm{I}$ & 0 \\
\hline \multicolumn{2}{|c|}{$\mathrm{I}$} & $1.5 \mathrm{I}$ & \multicolumn{2}{|c|}{$\mathrm{I}$} & $0.5 \mathrm{I}$ & $0.5 \mathrm{I}$ & \multicolumn{2}{|c|}{$\mathrm{I}$} & \multicolumn{2}{|c|}{$1.5 \mathrm{I}$} & \multicolumn{2}{c|}{$\mathrm{I}$} \\
\hline
\end{tabular}

T: Top B: Bottom

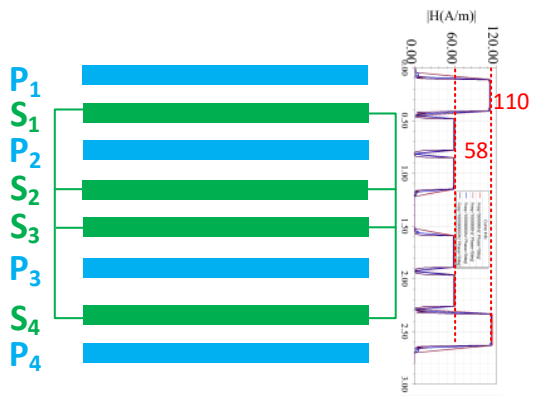

Fig.11. FEA simulated $\mathrm{H}$ field from $500 \mathrm{kHz}$ to $110 \mathrm{MHz}$ for Case IV

Three rules have to be applied to predict the current distribution for Case IV, namely $\mathrm{P}_{1}-\mathrm{S}_{1}-\mathrm{P}_{2}-\mathrm{S}_{2}-\mathrm{S}_{3}-\mathrm{P}_{3}-\mathrm{S}_{4}-\mathrm{P}_{4}$. Conductors $\mathrm{P}_{1}, \mathrm{P}_{2}$ and $\mathrm{P}_{3}$ in Case $\mathrm{V}$ are placed in the same locations with conductors $\mathrm{P}_{1}, \mathrm{P}_{2}$, and $\mathrm{P}_{3}$ in Case IV, respectively. The current distributions are also identical. Conductor $\mathrm{P}_{4}$ is attracted by the $\mathrm{S}_{4}$ and the current $I$ tends to the top surface. Comes to secondary windings. Following Rule 1 and Rule 3, conductor $\mathrm{S}_{1}$ carries $1.5 \mathrm{I}$ with $I$ on the top surface and $0.5 \mathrm{I}$ on the bottom surface. Conductor $\mathrm{S}_{4}$ conducts $1.5 I$ with $I$ on the bottom side and $0.5 I$ on the top side. Rule 2 is applied to conductors $S_{2}$ and $S_{3}$, which are adjacent to each other. This means that currents on $S_{2}$ and $S_{3}$ repel each other, but are attracted by the current $0.5 \mathrm{I}$ from conductors $\mathrm{P}_{2}$ and $\mathrm{P}_{3}$, respectively. Hence, conductor $\mathrm{S}_{2}$ carries $0.5 I$ on the top surface, while conductor $\mathrm{S}_{3}$ carries $0.5 \mathrm{I}$ on the bottom surface. TABLE II documents the current distribution for Case V.

FEA simulation is performed to verify the feasibility of the proposed approach. The absolute magnetic field distributions with frequency sweeping from $500 \mathrm{kHz}$ to $100 \mathrm{MHz}$ are given in Fig.12. The current assigned to every primary conductor is a sine wave with the amplitude 1A. Following Ampère's circuital law, the current amplitude can be easily calculated by $I=H b / N$. $117 \mathrm{~A} / \mathrm{m}$ corresponds to $1 \mathrm{~A}$ and $58.5 \mathrm{~A} / \mathrm{m}$ corresponds to $0.5 \mathrm{~A}$. The simulation results match the previous theoretical analyses. It also proves that the current distribution on every secondary layer is always constant when $h>>\delta_{w}$. $\mathrm{S}_{1}$, and $\mathrm{S}_{4}$ have the same current $1.5 \mathrm{~A}$ in Case IV. $\mathrm{S}_{2}$, and $\mathrm{S}_{3}$ have the identical current $0.5 \mathrm{~A}$.

Acknowledging the current distribution on each conductor, the winding loss and AC resistance $R_{a c}$ for each case can be calculated afterward. Previous efforts [25]-[29] have estimated the AC resistance of planar transformers. This paper utilizes the Dowell equation to calculate the AC resistance. Fig.13 shows comparisons between the calculated $\mathrm{AC}$ resistance and the FEA simulated AC resistance as a function of the frequency. It illustrates excellent agreement.

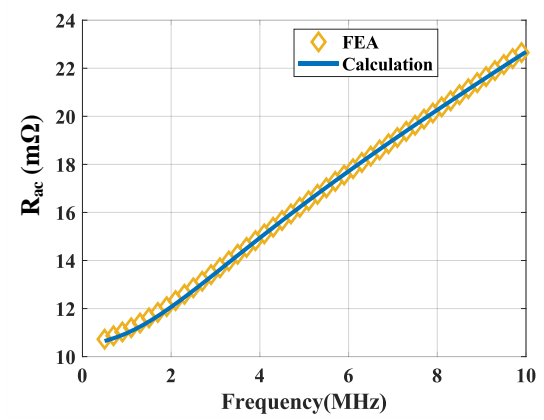

Fig.12. Comparison between the calculated AC resistance and FEA simulated AC resistance for Case IV

\section{EXTENSIONS TO OTHER WINDING STRUCTURES}

The proposed methodology used to predict the parallel current distribution is not limited to fully interleaved winding layout, but capable to be applied to many winding arrangements, such as partial-interleaved and non-interleaved winding structures.

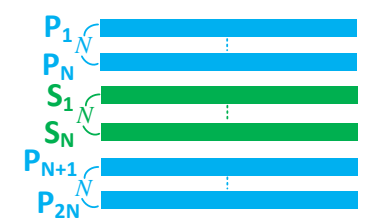

(a)

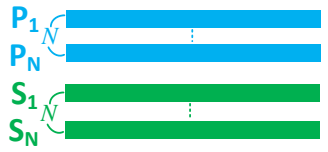

(b)
Fig.13. (a) Sandwiching winding arrangement and (b) non-interleaved winding arrangement

TABLE III

CURRENT DISTRIBUTION FOR SANDWICHING WINDING ARRANGEMENT

\begin{tabular}{|c|c|c|c|c|c|c|c|c|c|}
\hline \multicolumn{2}{|c|}{$\mathrm{P}_{\mathrm{T}}$} & \multicolumn{2}{c|}{$\mathrm{S}_{1}$} & \multicolumn{2}{c|}{$\mathrm{S}_{\text {other }}$} & \multicolumn{2}{c|}{$\mathrm{S}_{\mathrm{N}}$} & \multicolumn{2}{c|}{$\mathrm{P}_{\mathrm{B}}$} \\
\hline $\mathrm{T}$ & $\mathrm{B}$ & $\mathrm{T}$ & $\mathrm{B}$ & $\mathrm{T}$ & $\mathrm{B}$ & $\mathrm{T}$ & $\mathrm{B}$ & $\mathrm{T}$ & $\mathrm{B}$ \\
\hline 0 & $\mathrm{NI}$ & $\mathrm{NI}$ & 0 & 0 & 0 & 0 & $\mathrm{NI}$ & $\mathrm{NI}$ & 0 \\
\hline \multicolumn{2}{|c|}{$\mathrm{NI}$} & \multicolumn{2}{|c|}{$\mathrm{NI}$} & \multicolumn{2}{|c|}{0} & \multicolumn{2}{c|}{$\mathrm{NI}$} & \multicolumn{2}{c|}{$\mathrm{NI}$} \\
\hline
\end{tabular}

TABLE IV

CURRENT DISTRIBUTION FOR NON-INTERLEAVED WINDING ARRANGEMENT

\begin{tabular}{|c|c|c|c|c|c|c|c|}
\hline \multicolumn{2}{|c|}{$\mathrm{P}_{\mathrm{T}}$} & \multicolumn{2}{c|}{$\mathrm{S}_{1}$} & \multicolumn{2}{c|}{$\mathrm{S}_{\text {other }}$} & \multicolumn{2}{c|}{$\mathrm{S}_{\mathrm{N}}$} \\
\hline $\mathrm{T}$ & $\mathrm{B}$ & $\mathrm{T}$ & $\mathrm{B}$ & $\mathrm{T}$ & $\mathrm{B}$ & $\mathrm{T}$ & $\mathrm{B}$ \\
\hline 0 & $\mathrm{NI}$ & $\mathrm{NI}$ & 0 & 0 & 0 & 0 & 0 \\
\hline \multicolumn{2}{|c|}{ NI } & \multicolumn{2}{|c|}{ NI } & \multicolumn{2}{c|}{0} & \multicolumn{2}{c|}{0} \\
\hline
\end{tabular}

Fig.13(a) illustrates a sandwiched winding arrangement: $2 \mathrm{~N}$ primary turns are connected in series, while $2 N$ secondary conductors in parallel. Similar with previous analyses, Conductors $\mathrm{P}_{1}$ to $\mathrm{P}_{\mathrm{N}}$ and $\mathrm{P}_{\mathrm{N}+1}$ to $\mathrm{P}_{2 \mathrm{~N}}$ can be viewed as two separate conductors, namely $\mathrm{P}_{\mathrm{T}}$ and $\mathrm{P}_{\mathrm{B}}$, separately. $N I$ on conductor $\mathrm{P}_{\mathrm{T}}$ inclines to the bottom surface. $N I$ on conductor $\mathrm{P}_{\mathrm{B}}$ tends to the top surface. In secondary winding, following Rule 2 and Rule 3, conductors $\mathrm{S}_{1}$, and $\mathrm{S}_{\mathrm{N}}$ each conducts $N I$, but no current flows through any other layers between $S_{1}$ and $S_{N}$. The current distribution is shown in TABLE III.

The non-interleaved winding layout is shown in Fig.13(b). Similar with the previous process, the current distribution is derived and documented in TABLE IV.

From the above analyses, it can be concluded that it is useless to reduce the current density simply through more parallel conductors. Interleaved winding layouts are recommended to have a better current distribution. 


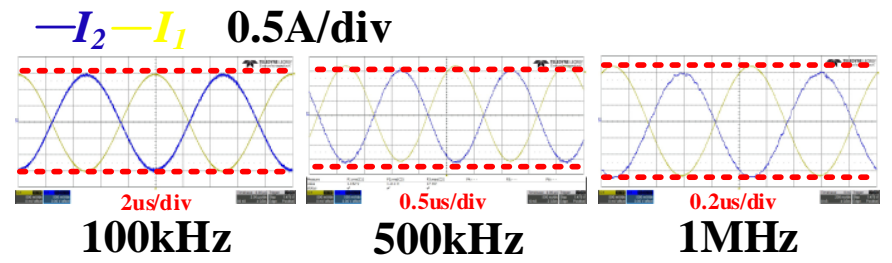

(a)

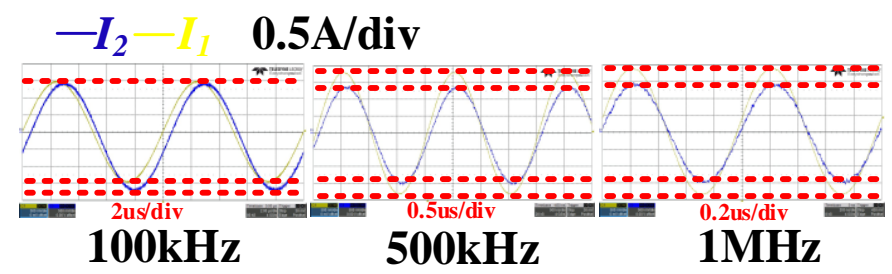

(b)

Fig.14. Current waveforms for (a) Case II P1-S2-S1-P2 and (b) Case III P1-S2P1-S1

TABLE V

WINDING DETAILES

\begin{tabular}{lc}
\hline \hline Parameters & Values \\
\hline Copper thickness $(h)$ & $70 \mu \mathrm{m}$ \\
Turn ratio $(n: 1)$ & $2: 1$ \\
Window width $(b)$ & $5.9 \mathrm{~mm}$ \\
Magnetic core & E22/6/16 \\
\hline \hline
\end{tabular}

\section{EXPERIMENT}

To verify the effectiveness of the theoretical analyses, two interleaved PCB winding layouts Case II $\mathrm{P}_{1}-\mathrm{S}_{2}-\mathrm{S}_{1}-\mathrm{P}_{2}$ and Case III $\mathrm{P}_{1}-\mathrm{S}_{2}-\mathrm{P}_{1}-\mathrm{S}_{1}$ were manufactured. TABLE $\mathrm{V}$ shows details about the transformer. The high-speed bipolar amplifier HSA4101 injected the sinusoidal current whose frequency changed from $100 \mathrm{kHz}$ to $1 \mathrm{MHz}$ to the primary winding. Secondary windings were short circuits. Current probes CWT Ultramini from PEM were used to measure the secondary currents. As shown in Fig.14, the parallel current waveforms for Case II and Case III were captured in different frequencies.

Analysis of Case II is given first. Fig.15 shows the measured RMS current ratio as a function of frequency. Each parallel conductor has an almost identical current. Recalling the theoretical analyses on Case II given in Section II, the same current is supposed to go through $S_{2}$ and $S_{1}$. Hence, the experiment results support the analytical solutions.

In Case III, Fig.16 shows the secondary RMS current on every parallel conductor over the average RMS current as a function of the frequency. The average RMS current is expressed by

$$
I_{R M S_{-} a v g}=\sqrt{\left(I_{1_{-} R M S}^{2}+I_{2_{-} R M S}^{2}\right) / 2}
$$

The RMS current ratios shown in Fig.16 do not match Fig.5 (b), which are supposed to be 1.5 and 0.5 for conductors $S_{2}$ and $S_{1}$, respectively. To further analyze this phenomenon, the PCB winding is cut off to measure the insulation thickness. Fig.17 represents the cross-section view of the PCB winding captured by the Micromanipulator 2210-LS. The insulation $t_{t}=0.543 \mathrm{~mm}$ is much larger than the $t_{b}=0.089 \mathrm{~mm}$. Taking the measured insulation thicknesses to (17) and (18), the calculated RMS current ratios as a function of frequency are plotted in Fig.16. It can be observed that calculations represent good agreement with experiment results at high frequency.
As a result, the experiment results support the theoretical analyses. The current distribution on parallel conductors is constant at high frequency. The insulation thickness significantly affects the current distribution.

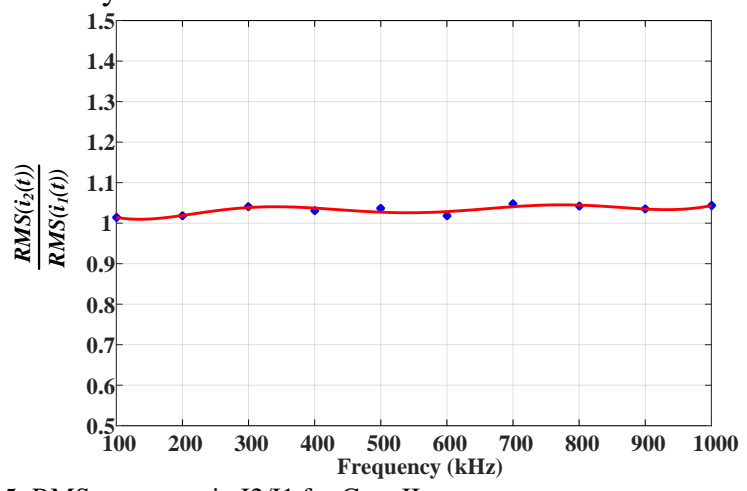

Fig.15. RMS current ratio I2/I1 for Case II

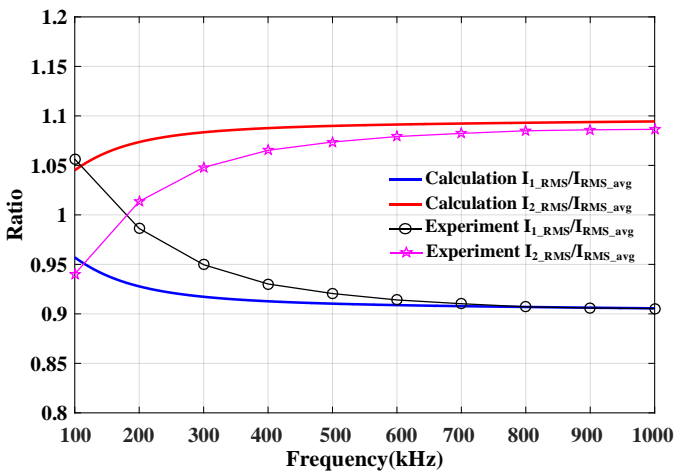

Fig.16. Case III calculated and experimental RMS current ratio $I_{R M S} I_{R M S \_a v g}$

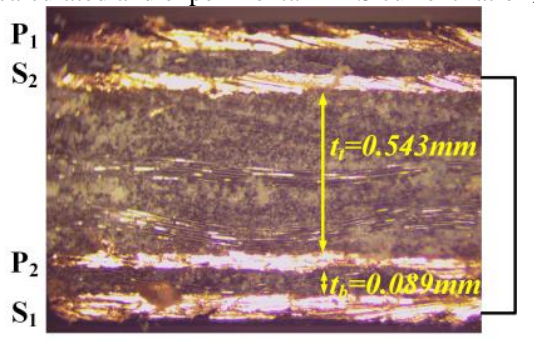

Fig.17. Case III P1-S2-P1-S1 cross section view of the PCB winding

\section{CONCLUSION}

This paper reveals that the current on every parallel conductor does not change with frequency when $h>>\delta_{w}$, and the interleaved winding layouts with different insulation thicknesses may result in a loss of the advantage of good current sharing. This paper proposes a methodology consisting of three rules to predict the parallel current distribution specifically for $N: 1$ transformers, which is supported by theoretical deductions and FEA simulations. No complex calculation algorithm or simulation tool is required, thereby greatly simplifying the winding loss calculation. The proposed methodology is not limited to the fully interleaved structures, but can be applied to many parallel schemes. The experiment further proves the effectiveness of the theoretical analyses on the effect of the 
insulation thickness and current distribution on parallel conductors at high frequency.

\section{APPENDIX}

The current expressions $i_{1}(t)$ and $i_{2}(t)$ for Case $\mathrm{I}$ are represented in (A.1) and (A.2), respectively.

\section{REFERENCES}

[1] Z. Ouyang, W. G. Hurley, and M. A. Andersen, "Improved Analysis and Modeling of Leakage Inductance for Planar Transformers," IEEE Journal of Emerging and Selected Topics in Power Electronics, vol. 7, no. 4, pp. 22252231, 2019.

[2] M. T. Quirke, J. J. Barrett, and M. Hayes, "Planar magnetic component technology - A review," IEEE Trans. Compon. Hybrids, Manuf. Technol.,vol. 15, no. 5, pp. 884-892, Oct. 1992.

[3] N. Dai, A. W. Lofti, G. Skutt, W. Tabisz, and F.C. Lee, "A comparative study of high-frequency, low-profile planar transformer technologies," in Proc. IEEE Appl. Power Electron. Conf. Expo., Feb. 1994, vol. 1, pp. 226-232.

[4] A. M. Urling, V. A. Niemela, G. R. Skutt, and T. G. Wilson, "Characterizing high-frequency effects in transformer windings - A guide to several significant articles," in Proc. IEEE Appl. Power Electron. Conf. Expo., Mar. 13-17, 1989, pp. $373-385$.

[5] D. J. Perreault, J. Hu, J. M. Rivas, Y. Han, O. Leitermann, R. C. N. PilawaPodgurski, A. Sagneri, and C. R. Sullivan, "Opportunities and challenges in very high frequency power conversion," in Proc. IEEE Appl. Power Electron. Conf. Expo., Feb. 2009, pp. 1-14.

[6] C. R. Sullivan, D. V. Harburg, J. Qiu, C. G. Levey, and D. Yao, "Integrating magnetics for on-chip power: A perspective," IEEE Trans. Power Electron., vol. 28, no. 9, pp. 4342-4353, Sep. 2013.

[7] C. Fei, F. C. Lee, and Q. Li, "High-efficiency high-power-density LLC converter with an integrated planar matrix transformer for high output current applications," IEEE Trans. Ind. Electron., vol. PP, no. 99, pp. 1-1, 2017.

[8] M. H. Ahmed, C. Fei, F. C. Lee, and Q. Li, "Single-stage high-efficiency 48/1 V Sigma converter with integrated magnetics," IEEE Trans. Ind. Electron., vol. 67, no. 1, pp. 192-202, Jan. 2020.

[9] Y. Ren, M. Xu, K. Yao, and F. Lee, "Two-stage $48 \mathrm{~V}$ power pod exploration for 64-bit microprocessor," in Proc. IEEE Appl. Power Electron. Conf. and Expo., Miami Beach, USA, 9-13 Feb.2003

[10] M. Li, Z. Ouyang, M. Andersen, “A Hybrid Multitrack-Sigma Converter with Integrated Transformer for Wide Input Voltage Regulation," in Proc. IEEE Appl. Power Electron. Conf. Expo. APEC, Feb. 2020.

[11] C. Fei, M. H. Ahmed, F. C. Lee, Q. Li, "Two-stage 48V-12V/6V $1.8 \mathrm{~V}$ Voltage Regulator Module with Dynamic Bus Voltage Control for Light Load Efficiency Improvement," in IEEE Transactions on Power Electronics , vol.32, no.7, pp.5628-5636

[12] M. H. Ahmed, C. Fei, F. C. Lee, and Q. Li, " $48-\mathrm{V}$ voltage regulator module with PCB winding matrix transformer for future data centers," IEEE Trans. Ind. Electron., vol. 64, no. 12, pp. 9302-9310, Dec. 2017

[13] M. Li, Z. Ouyang and M. A. E. Andersen, "Analysis and Optimal Design of High Frequency and High Efficiency Asymmetrical Half-Bridge Flyback Converters," in IEEE Transactions on Industrial Electronics.

[14] X. Margueron, A. Besri, Y. Lembeye, and J.-P. Keradec, "Current sharing between parallel turns of a planar transformer: Prediction and improvement using a circuit simulation software," IEEE Trans. Ind. Appl., vol. 46, no. 3, pp. 1064-1071, May/Jun. 2010.

[15] D. Fu, F. C. Lee and S. Wang, "Investigation on transformer design of high frequency high efficiency dc-dc converters," 2010 Twenty-Fifth Annual IEEE Applied Power Electronics Conference and Exposition (APEC), Palm Springs, CA, 2010, pp. 940-947.

[16] Z. Ouyang, O. C. Thomsen and M. A. E. Andersen, "Optimal Design and Tradeoff Analysis of Planar Transformer in High-Power DC-DC Converters," in IEEE Transactions on Industrial Electronics, vol. 59, no. 7, pp. 2800-2810, July 2012.
[17] Z. Ouyang and M. A. E. Andersen, "Overview of Planar Magnetic Technology_Fundamental Properties," in IEEE Transactions on Power Electronics, vol. 29, no. 9, pp. 4888-4900, Sept. 2014.

[18] A. F. Goldberg, J. G. Kassakian, and M. F. Schlecht, "Finite-element analysis of copper loss in $1-10 \mathrm{MHz}$ transformers," IEEE Trans. Power Electron., vol. 4, no. 2, pp. 157-167, Apr. 1989.

[19] N. Y. Abed and O. A. Mohammed, "Physics-based high-frequency transformer modeling by finite elements, IEEE Trans. Magn., vol. 46, no. 8, pp. 3249-3252, Aug. 2010

[20] R. Asensi, R. Prieto, J. A. Cobos, and J. Uceda, "Modeling high-frequency multiwinding magnetic components using finite-element analysis,"IEEE Trans. Magn., vol. 43, no. 10, pp. 3840-3850, Oct. 2007.

[21] J. G. Hayes, N. O'Donovan, and M. G. Egan, "The extended T model of the multiwinding transformer," in Proc. IEEE Power Electron. Spec. Conf., Jun. 20-25, 2004, vol. 3, pp. 1812-1817.

[22] J. D. Jr, van Wyk, W. A. Cronje, J. D. van Wyk, C. K. Campbell, and P. J. Wolmarans, "Power electronic interconnects: Skin- and proximity-effectbased frequency selective-multipath propagation," IEEE Trans. Power Electron., vol. 20, no. 3, pp. 600-610, May 2005

[23] M. Chen, M. Araghchini, K. K. Afridi, J. H. Lang, C. R. Sullivan and D. J. Perreault, "A Systematic Approach to Modeling Impedances and Current Distribution in Planar Magnetics," in IEEE Transactions on Power Electronics, vol. 31, no. 1, pp. 560-580, Jan. 2016.

[24] Wei Chen, Yipeng Yan, Yuequan Hu and Qing Lu, "Model and design of PCB parallel winding for planar transformer," in IEEE Transactions on Magnetics, vol. 39, no. 5, pp. 3202-3204, Sept. 2003.

[25] J. H. Spreen, "Electrical terminal representation of conductor loss in transformers," IEEE Trans. Power Electron., vol. 5, no. 4, pp. 424-429, Oct. 1990.

[26] W. G. Hurley and M. C. Duffy, "Calculation of self and mutual impedances in planar magnetic structures,” IEEE Trans. Magn., vol. 31, no. 4, pp. 2416-2422, Jul. 1995.

[27] W. G. Hurley, E. Gath, and J. G. Breslin, "Optimizing the AC resistance of multilayer transformer windings with arbitrary current waveforms," IEEE Trans. Power Electron., vol. 15, no. 2, pp. 369-376, Mar. 2000

[28] C. R. Sullivan, "Computationally efficient winding loss calculation with multiple windings, arbitrary waveforms, and two-dimensional or three dimensional field geometry," IEEE Trans. Power Electron., vol. 16, no. 1, pp. 142-150, Jan. 2001.

[29] P. L. Dowell, "Effects of eddy currents in transformer windings," in Proceedings of the Institution of Electrical Engineers, vol. 113, no. 8, pp. 1387 1394, August 1966.

$$
\begin{gathered}
i_{i}(t)=-2 I_{p} \gamma \rho \frac{\sin (w t)(\cosh (2 \gamma h)+\sinh (2 \gamma h)+1)-\cosh (2 \gamma h)+2 \sinh (\gamma h)+2 \cosh (\gamma h)-\sinh (2 \gamma h)-1}{\left(j \cdot t_{h} u_{o} w-2 \rho \gamma\right)(\cosh (2 \gamma \rho)+\sinh (2 \gamma \rho))-j t_{h} u_{o} w-2 \rho \gamma} \\
i_{2}(t)=2 I_{p} \frac{\left[\left(j \cdot t_{h} u_{o} w-\gamma \rho\right) \sin (w t)-\gamma \rho\right](\cosh (2 \gamma h)+\sinh (2 \gamma h))-\left(j \cdot t_{h} u_{o} w-\gamma \rho\right) \sin (\mathrm{wt})+2 \gamma \rho\left(\cosh (\gamma h)+\sinh (\gamma h)-\frac{1}{2}\right)}{\left(j \cdot t_{h} u_{o} w-2 \gamma \rho\right)(\cosh (2 \gamma \rho)+\sinh (2 \gamma \rho))-j t_{h} u_{o} w-2 \gamma \rho}
\end{gathered}
$$

